\title{
ASMASE IS REQUIRED FOR CHRONIC ALCOHOL INDUCED HEPATIC ENDOPLASMIC RETICULUM STRESS AND MITOCHONDRIAL CHOLESTEROL LOADING
}

\author{
Anna Fernandez ${ }^{1,2,{ }^{*}, \text { Núria Matias }}{ }^{1,2,{ }^{*}, \text { Raquel Fucho }}{ }^{1,2}$, Vicente Ribas ${ }^{1,2}$, Claudia Von \\ Montfort $^{1,2}$, Natalia Nuño ${ }^{1,2, \dagger}$, Anna Baulies ${ }^{1,2}$, Laura Martinez $z^{1,2}$, Núria Tarrats ${ }^{1,2}$, \\ Montserrat Mari $^{1,2}$, Anna Colell ${ }^{1,2}$, Albert Morales ${ }^{1,2}$, Laurent Dubuquoy ${ }^{3}$, Philippe \\ Mathurin $^{3}$, Ramón Bataller ${ }^{2, \dagger}$, Joan Caballeria ${ }^{2}$, Montserrat Elena ${ }^{4}$, Jesus Balsinde ${ }^{5}$, Neil \\ Kaplowitz $^{6}$, Carmen Garcia-Ruiz ${ }^{1,2, \# \text {, and Jose C. Fernandez-Checa }}{ }^{1,2,6, \#}$ \\ ${ }^{1}$ Department of Cell Death and Proliferation, IIBB-CSIC \\ ${ }^{2}$ Liver Unit-Hospital Clinic-IDIBAPS, and CIBEREHD, Barcelona, Spain \\ 3Université Lille Nord de France, and Service des Maladies de l'Appareil Digestif, Hôpital Huriez, \\ Lille, France; Unité 995, Institut National de la Santé et de la Recherche Médicale, Lille, France \\ ${ }^{4}$ Biochemical Service, Hospital Clinic, Barcelona, Spain \\ ${ }^{5}$ Institut of Molecular Biology and Genetics, CSIC-CIBERDEM, Valladolid, Spain \\ ${ }^{6}$ Southern California Research Center for ALPD and Cirrhosis, Keck School of Medicine of the \\ University of Southern California, Los Angeles, CA 90033
}

\section{Abstract}

Background \& aims-The pathogenesis of alcohol-induced liver disease (ALD) is poorly understood. Here, we examined the role of acid sphingomyelinase (ASMase) in alcohol induced hepatic endoplasmic reticulum (ER) stress, a key mechanism of ALD

Methods-We examined ER stress, lipogenesis, hyperhomocysteinemia, mitochondrial cholesterol (mChol) trafficking and susceptibility to LPS and concanavalin-A in ASMase ${ }^{-1-}$ mice fed alcohol.

Results-Alcohol feeding increased SREBP-1c, DGAT-2 and FAS mRNA in ASMase ${ }^{+/+}$but not in $\mathrm{ASMase}^{-/-}$mice. Compared to ASMase ${ }^{+/+}$mice, $\mathrm{ASMase}^{-/-}$mice exhibited decreased expression of ER stress markers induced by alcohol, but the level of tunicamycin-mediated upregulation of ER stress markers and steatosis was similar in both types of mice. The increase in homocysteine levels induced by alcohol feeding was comparable in both ASMase ${ }^{+/+}$mice and $\mathrm{ASMase}^{-/-}$mice. Exogenous ASMase, but not neutral SMase, induced ER stress by perturbing ER $\mathrm{Ca}^{2+}$ homeostasis. Moreover, alcohol-induced mChol loading and StARD1 overexpression were

(C) 2013 European Association of the Study of the Liver. Published by Elsevier B.V. All rights reserved.

\#Carmen Garcia-Ruiz and Jose C Fernandez-Checa share senior authorship. Correspondence addressed to Jose C Fernandez-Checa, checa229@yahoo.com.

*Anna Fernandez and Núria Matias share equal contribution to this paper.

†N.L. current address: Departamento Ciencias Salud, División Ciencias Biológicas y de la Salud, Univeridad Autónoma Metropolitana-Iztapalapa, Mexico DF, Mexico. R.B. current address: Department of Medicine and Nutrition, University of North Carolina, Chapel Hill, NC USA.

Publisher's Disclaimer: This is a PDF file of an unedited manuscript that has been accepted for publication. As a service to our customers we are providing this early version of the manuscript. The manuscript will undergo copyediting, typesetting, and review of the resulting proof before it is published in its final citable form. Please note that during the production process errors may be discovered which could affect the content, and all legal disclaimers that apply to the journal pertain. 
blunted in ASMase ${ }^{-/-}$mice. Tunicamycin upregulated StARD1 expression and this outcome was abrogated by tauroursodeoxycholic acid. Alcohol-induced liver injury and sensitization to LPS and concanavalin-A were prevented in ASMase ${ }^{-/}$mice. These effects were reproduced in alcohol-fed TNFR1/R2 ${ }^{-/-}$mice. Moreover, ASMase does not impair hepatic regeneration following partial hepatectomy. Of relevance, liver samples from patients with alcoholic hepatitis exhibited increased expression of ASMase, StARD1 and ER stress markers.

Conclusion-Our data indicate that ASMase is critical for alcohol-induced ER stress, and provide a rationale for further clinical investigation in ALD.

\section{Introduction}

Alcohol-induced liver disease (ALD) is a major cause of chronic liver disease and related death in western countries. Unfortunately, little progress has been made in ALD treatment due to the incomplete understanding of ALD pathogenesis and progression from hepatic steatosis to advanced stages, i.e. alcoholic hepatitis (AH) [1,2]. Alcohol triggers lipogenesis and liver injury by several mechanisms, including perturbed $\mathrm{NAD}^{+} / \mathrm{NADH}$, acetaldehyde generation, adiponectin downregulation, hyperhomocysteinemia and mitochondrial dysfunction [2-7]. Endoplasmic reticulum (ER) stress has emerged as a key event in ALD, contributing to steatosis and liver injury [4]. Early work indicated a critical role for TNF in ALD and increased hepatic TNF levels and TNFR1 expression have been reported in patients with ALD [8, 9]. Moreover, alcohol intake has been shown to sensitize to TNFinduced hepatocellular death $[10,11]$.

Ceramide has been extensively studied in relation to stress and cell death [12, 13]. In addition to de novo synthesis in the ER, ceramide can be generated by sphingomyelin (SM) hydrolysis by sphingomyelinases (SMases) [14]. Although, the neutral SMase (NSMase) has been shown to induce apoptosis $[15,16]$, this outcome may be dependent on the topology/ sidedness of NSMase-induced ceramide generation [17]. Moreover, acid SMase (ASMase) mediates apoptosis in response to cell death receptors, chemotherapy or ionizing radiation [18-20]. ASMase is activated in TNF receptosomes by proteolytic cleavage of pro-ASMase due to sequential activation of caspase-8 and caspase-7 [21]. In addition to its role in cell death, ASMase has emerged as a critical player in liver fibrosis by regulating lysosomal cathepsins B/D [22].

Chronic alcohol feeding has been shown to activate ASMase, contributing to hepatic steatosis [23, 24]. However, the role of ER stress in these studies was not examined, specifically if ASMase was required for the engagement of this key pathway in ALD. Further, these reports did not address the role of ASMase in alcohol-induced mitochondrial cholesterol (mChol) trafficking, which contributes to TNF susceptibility [25], or liver regeneration. To critically examine the contribution of ASMase to ALD, we analyzed the response of ASMase ${ }^{-/}$mice to oral alcohol feeding. We show that ASMase is required for alcohol-induced ER stress and consequent activation of lipogenic pathways. Moreover, $\mathrm{ASMase}^{-/-}$mice are resistant to alcohol-induced mChol loading and mitochondrial GSH (mGSH) depletion. Of relevance, ASMase does not impair liver regeneration after partial hepatectomy and liver samples from patients with acute AH display increased expression of ASMase and ER stress markers. Overall, ASMase is a critical player in ALD by inducing ER stress. 


\section{Materials and Methods}

\section{Animals and Treatments}

All procedures were approved by the ethics committee of the University of Barcelona and conducted according to institutional guidelines. ASMase ${ }^{-/}$mice (C57BL/6 strain, a generous gift from R. Kolesnick and E. Gulbins) have been characterized previously [19]. TNFR1 $1^{-I-}$, TNFR2 $2^{-/-}$, and double TNFR1/R2 ${ }^{-/-}$mice (C57BL/6 strain) were generated and characterized as described [26]. Male knockout mice and control littermates ASMase $^{+/+}$or TNFRs $\left.^{+/+}\right)(8-10$ weeks old) were pair fed control or ethanol-containing liquid diets (Test Diet, cat no: LD101 and LD101A, respectively), providing 36\% of calories from ethanol (or maltose), $35 \%$ of calories from fat, $18 \%$ of calories from protein, and $11.5 \%$ of calories from carbohydrate, as described previously [10]. The ethanol diet was introduced gradually by increasing the ethanol content of the diet by $1 \%$ (vol/vol) every 2 days until mice consumed diets containing 5\% ( $\mathrm{vol} / \mathrm{vol}$ ) ethanol. All mice were then fed the liquid diet containing 5\% ethanol for 4 weeks. In some cases, betaine $(1.5 \% \mathrm{wt} / \mathrm{vol})$ was administered to wild type mice during alcohol feeding as described [27]. Moreover, to address the role of cholesterol on SREBP-2-mediated gene expression, wild type mice were fed a high cholesterol (HC, $2 \%$ cholesterol) diet for 2 days as described [25]. Sample processing for analyses is described in Supplementary Methods.

\section{Partial hepatectomy}

To examine the impact of ASMase inhibition on liver regeneration, wild type mice were treated with amitriptyline i.p. for $(2.5 \mathrm{mg} / \mathrm{kg})$ for 10 days before partial hepatectomy. Mice were anesthetized with a $92: 7 \mathrm{mg} / \mathrm{kg}$ mix of ketamine:xylazine and subjected to midventral laparotomy with 70\% liver resection (left lower and upper and right upper lobes), and the weight of the excised liver was determined. Sham surgery entailed midventral laparotomy. Survival was higher than $80 \%$ and all deaths were due to post-surgery complications during the first $24 \mathrm{~h}$ post-PH. Hepatocyte proliferation was determined by PCNA staining at different time points and liver regeneration index was calculated as the ratio of the liver remnant to body mass and $\times 100$ ).

\section{Human liver samples}

Patients gave written consent in accordance with the Declaration of Helsinki, and the protocol, approved by ethical committees from the Hospital Clinic and Hopital Huriez, followed ethical guidelines on handling of human samples. Liver samples were obtained from patients with AH by transyugular biopsies $(\mathrm{n}=10)$ or from explanted livers from patients undergoing liver transplantation for alcoholic liver disease $(n=7)$. Normal livers were obtained from cadaveric liver donors $(n=4)$ or from resection for unrelated liver diseases (metastasis from distant organ cancer, $n=8$ ). Patients characteristics are shown in Supplementary Figure 1, and description for RNA isolation is shown in Supplementary Methods.

\section{Results}

\section{ASMase deficiency prevents alcohol-induced lipogenesis and macrosteatosis}

We examined the effect of ASMase deficiency in the expression of lipogenic enzymes. Alcohol feeding to ASMase ${ }^{+/+}$mice increased the expression of transcription factor SREBP-1c and target enzymes, including DGAT-2 and FAS (Figure 1A-C). Alcohol also increased expression of SREBP-2, (Figure 1D). Interestingly, SREBP-1c, DGAT-2 and FAS induction by alcohol were blunted in ASMase ${ }^{-/-}$mice fed alcohol (Figure 1A-C). However, $\mathrm{ASMase}^{-/-}$mice fed control diet exhibited increased expression of SREBP-2 that was increased by alcohol feeding (Figure 1D). 
These findings translated in increased TG and FFA levels and macrosteatosis in ASMase $\mathrm{A}^{+/+}$ mice, but not ASMase ${ }^{-/-}$mice (Supplemental Figure 1A-C). Alcohol increased SM and cholesterol levels in ASMase ${ }^{+/+}$mice (Supplemental Figure 1D, E), which displayed higher filipin staining (Supplemental Figure 1F). ASMase ${ }^{-/-}$mice fed control diet exhibited increased hepatic SM and cholesterol content compared to ASMase ${ }^{+/+}$mice (Supplemental Figure 1D, E). Upon ethanol feeding, SM and cholesterol levels further increased in ASMase $^{-/-}$mice (Supplemental Figure 1D, E, F). ASMase deficiency did not perturb alcohol metabolism as blood alcohol levels were comparable in ASMase $^{+/+}$mice and ASMase $^{-/-}$mice fed alcohol $(117 \pm 12 \mathrm{mg} / \mathrm{dl}$ and $125 \pm 13 \mathrm{mg} / \mathrm{dl}$, respectively). Furthermore, CYP2E1 upregulatation following alcohol feeding was similar in both types of mice (Supplementary Figure S2). Although the liver/body weight increased in ASMase ${ }^{-/}$mice, this increment in response to alcohol feeding was similar between ASMase ${ }^{+/+}$mice and ASMase $^{-/-}$mice (Supplementary Figure 2). The hepatomegaly seen in the null mice likely reflects the accumulation of lipids such as sphingomyelin and cholesterol as well as massive lysosomal proliferation reflected by increased LAMP2 expression and characteristic foam cells formation (not shown). Thus, these findings indicate that the genetic ablation of ASMase increases hepatic SM and cholesterol but prevents alcohol-induced TG, FFA accumulation and macrosteatosis.

\section{ASMase is required for alcohol-induced ER stress}

ER stress and the unfolded protein response (UPR) are critical adaptive mechanisms to metabolic alterations in the liver, especially in the context of lipid metabolism [28, 29]. Alcohol intake has been shown to induce ER stress [4, 27], which contributes to fatty liver [30]. As expected, alcohol-fed ASMase ${ }^{+/+}$mice showed increased upregulation of ER stress markers, GRP78, PDI, CHOP, ATF4 and IRE1, at the mRNA and protein level. However, this response was abrogated in ASMase ${ }^{-/}$mice (Figure 1E-I). Since ASMase is an intermediate in TNF signaling [19,21], and since the role of individual TNF receptors on alcohol-mediated ER stress has not been previously reported, we examined the response of TNFR $1^{-/}, \mathrm{TNFR}^{-/-}$and TNFR1/R2 ${ }^{-/-}$mice to alcohol-mediated ER stress. As seen, double TNFR1/R2 ${ }^{-/}$mice did not exhibit signs of alcohol-induced ER stress, and this response was largely reproduced by the lack of either TNFR $1^{-/}$or TNFR2 $2^{-/}$

(Supplemental Figure 3A-D). Furthermore, in vivo tunicamycin treatment induced ER stress (Figure 1J) and hepatic steatosis (Figure 1K) independently of ASMase. Tunicamycin increased TG levels from $73 \pm 7.8$ and $82 \pm 9.7 \mathrm{~g} / \mathrm{mg}$ protein to $190 \pm 8.9$ and $178 \pm 12.8 \mathrm{~g} / \mathrm{mg}$ protein, in ASMase ${ }^{+/+}$and ASMase ${ }^{-/}$mice, respectively. Moreover, similar findings have been observed in isolated hepatocytes from ASMase ${ }^{+/+}$and ASMase $^{-/}$mice challenged with the bacterial toxin subtilisin AB5 (manuscript in preparation), which induces ER stress by downregulating GRP78 [30]. These results suggest that the resistance of ASMase ${ }^{-/-}$mice to alcohol-induced ER stress is not due to an inherent defect in the ER stress response.

\section{Resistance of ASMase ${ }^{-/-}$mice to alcohol-induced ER stress is independent of hyperhomocysteinemia}

To explore putative mechanisms for the resistance of ASMase null mice to alcohol-induced ER stress, we analyzed metabolites of the methionine cycle, in particular, hom ocysteine, which has been shown to contribute to alcohol-induced ER stress [4, 27]. Intriguingly, alcohol increased plasma Hcy levels both in $\mathrm{ASMase}^{+/+}$and $\mathrm{ASMase}^{-/-}$mice (Supplementary Figure 4A). Alcohol decreased S-adenosylmethionine (SAM) to Sadenosylhomocysteine (SAH) ratio and $M S$ mRNA levels in control and ASMase ${ }^{-/-}$mice (Supplementary Figure 4B), without effect on BHMT expression (Supplementary Figure 4C-D). Betaine supplementation to wild-type mice prevented alcohol-induced hyperhomocysteinemia (from $9.5 \mathrm{nmolHcy} / \mathrm{ml}$ to $4.8 \mathrm{nmolHcy} / \mathrm{ml}$ ) but did not abolish alcohol-stimulated ASMase activation and ER stress (not shown). In addition, the expression 
of liver-specific MAT1 A mRNA increased in ASMase $^{+/+}$and ASMase ${ }^{-/}$mice fed alcohol (Supplementary Figure 4E), while $C B S$ expression increased in $\mathrm{ASmase}^{+/+}$but not $\mathrm{ASMase}^{-/-}$alcohol-fed mice (Supplementary Figure 4F). The increase in Hcy levels by alcohol intake was independent of TNFR1 or TNFR2 (Supplementary Figure 5). Overall, our findings indicating that the resistance of ASMase null mice to alcohol-induced ER stress is independent of hyperhomocysteinemia are consistent with data showing that ASMase is required for homocysteine-induced glomerular injury in $\mathrm{CBS}^{-/-}$mice [31] and suggest that hyperhomocysteinemia plays a minor role in alcohol-induced ER stress.

\section{Exogenous ASMase induces ER stress and decreases thapsigargin-induced ER $\mathrm{Ca}^{2+}$ release}

Although the de novo ceramide synthesis has been linked to ER stress [32, 33], the role of ASMase on ER stress has not been examined. Alcohol feeding stimulated ASMase activity and increased total hepatic ceramide levels in $\mathrm{ASMase}^{+/+}$mice (Supplemental Figure 6A, B), without activation of NSMase. Moreover, MS analyses indicated a predominant increase in C16:0 and C18:0 ceramide species (64\% and 52\%, respectively) and a relatively minor increase in C24:0 (23\%) in ASMase ${ }^{+/+}$mice fed alcohol, while these species decreased in alcohol-fed ASMase ${ }^{-/-}$mice (not shown). However, alcohol-induced ceramide generation was blunted in ASMase ${ }^{-/}$mice (Supplemental Figue 6B). The induction of Sgms1 and Sgms 2 by alcohol intake was similar in ASMase ${ }^{+/+}$and $\mathrm{ASMase}^{-/-}$mice (Supplementary Figure 7A, B), likely accounting for the increase in SM by alcohol in wild type mice despite increased ceramide generation.

To investigate the role of ASMase in alcohol-induced ER stress, we cultured HepG2 cells with exogenous ASMase or NSMase. Both enzymes increased ceramide levels by $2-3$ fold peaking by 60 minutes, in agreement with previous findings [34]. Exposure of HepG2 cells to exogenous ASMase (18 hours), but not NSMase, increased expression of ER stress markers (Supplemental Figure 6C-F), indicating the specificity of SMases to cause ER stress. Similar upregulation of ER stress markers was observed in primary mouse hepatocytes exposed to exogenous ASMase but not NSMase (not shown), indicating that the ability of exogenous ASMase to induce ER stress is independent of the type of cells used. Since ER $\mathrm{Ca}^{2+}$ stores regulates UPR and ER stress, we determined ER $\mathrm{Ca}^{2+}$ homeostasis in HepG2 cells in response to exogenous ASMase. Addition of thapsigargin, a specific inhibitor of the ER Ca ${ }^{2+}$ pump SERCA, to control HepG2 cells released $\mathrm{ER} \mathrm{Ca}^{2+}$ stores towards the cytosol. However, exogenous ASMase (1hour) decreased the thapsigarginstimulated $\mathrm{Ca}^{2+}$ release, indicating lower ER Ca ${ }^{2+}$ storage (Supplemental Figure 6G, H). Thus, these findings suggest that alcohol-induced ASMase activation induces ER stress, at least in part, by disrupting $\mathrm{ER} \mathrm{Ca}^{2+}$ homeostasis.

\section{ASMase ${ }^{-1-}$ mice are resistant to alcohol-induced $\mathrm{mChol}$ trafficking due to defective StARD1 upregulation}

Since wild type mice and ASMase knockout mice exhibited increased hepatic free cholesterol content upon alcohol feeding, we next examined its trafficking to mitochondria, as this process has been shown to regulate cell death and steatohepatitis due to mitochondrial GSH depletion [25, 35], which has been reported in ALD models [36-38]. mChol loading was observed in cultured hepatocytes from ASMase ${ }^{+/+}$mice fed alcohol as indicated by the merged fluorescence of filipin, a fluorescent polyene antibiotic, which binds specifically to the 3 -hydroxyl group of steroids [25], and cytochrome $\mathrm{c}$ to stain mitochondria; however, this process was defective in hepatocytes from alcohol-fed ASMase $^{-/-}$mice (Figure 2A, B). To account for this unexpected finding, we analyzed the expression of proteins that regulate mChol homeostasis, including members of the StARD family of carriers, in particular StARD1, known to regulate mitochondrial cholesterol 
homeostasis and trafficking between mitochondrial outer to inner membranes [39, 40]. Alcohol induced the expression of StARD1 in $\mathrm{ASMase}^{+/+}$mice but not $\mathrm{ASMase}^{-/-}$mice (Figure 2C), without changes in MLN64 (also known as StARD3) mRNA levels (Figure 2D). Moreover, endogenous expression of caveolin-1, which has been shown to regulate mChol homeostasis [35], was similar for ASMase ${ }^{+/+}$and ASMase $^{-/-}$mice, although alcohol feeding increased caveolin-1 mRNA levels in $\mathrm{ASMase}^{-/-}$mice (Figure 2E). Consistent with these findings, alcohol increased mChol in $\mathrm{ASMase}^{+/+}$but not ASMase ${ }^{-/-}$mice (Figure 2F), resulting in mGSH depletion (Figure $2 \mathrm{G}$ ) and decreased membrane fluidity (not shown).

We next explored if ER stress regulates StARD1 expression. In parallel with induced expression of Chop, Pdi and Grp78 (not shown), tunicamycin increased SREBP-2 and StARD1 mRNA levels (Figure 2G-H). Pretreatment with TUDCA, a chemical chaperone that prevents ER stress [41], abrogated tunicamycin-induced expression of SREBP-2 and StARD1 (Figure 2H, I). To confirm that StARD1 is an ER stress but not SREBP-2 regulated gene, we fed mice a high cholesterol diet (HC) as described before [25]. As expected for SREBP-2-targeted genes, HC feeding decreased the expression of HMG-CoA reductase and SREBP-2 but not StARD1 (Supplementary Figure 8). Thus, these results uncovered a previously unrecognized role for ASMase in the regulation of mChol trafficking in association with StARD1 expression.

\section{ASMase ablation blunts alcohol-mediated susceptibility to LPS and ConA}

We next examined susceptibility of alcohol-fed ASMase ${ }^{-/-}$mice to low dose LPS or concanavalin-A challenging. Endogenous liver damage to alcohol intake was modest in $\mathrm{ASMase}^{+/+}$mice and reduced in ASMase ${ }^{-/-}$mice (Figure 3A). However, alcohol sensitized $\mathrm{ASMase}^{+/+}$mice but not ASMase ${ }^{-/-}$mice to LPS and concanavalin-A-mediated liver damage (Figure 3A-D), consistent with previous findings [42]. LPS treatment resulted in increased inflammatory cell infiltration reflected by myeloperoxidase staining in ASMase ${ }^{+/+}$ but not ASMase ${ }^{-/-}$mice fed alcohol (not shown). Moreover, cultured hepatocytes from ASMase $^{+/+}$but not ASMase ${ }^{-/}$mice exhibited enhanced susceptibility to TNF-induced cell death (Figure 3E). Furthermore, TNFR1 ${ }^{-/-}$mice were resistant to concanavalin-A-mediated liver damage following alcohol feeding, with similar findings observed for LPS challenge (Figure 3F, G). Thus, ASMase determines alcohol-induced liver damage and sensitization to circulating and cell-bound TNF.

\section{ASMase antagonism protects against alcohol-induced ER stress and TNF susceptibility and does not impair liver regeneration}

We next tested the role amitriptyline, which prevents the proteolytic maturation of proASMase [43, 44], in alcohol-induced ER stress and LPS susceptibility. Amitriptyline significantly inhibited (>80\%) the activation of ASMase by alcohol feeding in wild type mice (Supplemental Figure 6A). Importantly, amitriptyline treatment decreased alcoholinduced macrosteatosis (Figure 4A) and accumulation of TG, FFA (Figure 4B-C), without causing SM and cholesterol accumulation observed in $\mathrm{ASMase}^{-/-}$mice (not shown). Moreover, amitriptyline ameliorated alcohol-induced sensitization to LPS (Figure 4D) and concanavalinA-mediated liver damage (not shown), as well as the activation of ER stress markers PDI and phosphorylated IRE1 (Figure 4E). However, amitriptyline did not prevent alcohol-induced hyperhomocysteinemia, further suggesting that ASMase itself modulates ER stress. Since liver regeneration modulates ALD, we next asked whether ASMase inhibition by amitriptyline modulates liver regeneration following partial hepatectomy (PH). Hepatocyte proliferation examined by PCNA staining and the final liver mass after PH in wild type mice were unaffected by ASMase inhibition with amitriptyline (Figure 4D, E). Moreover, liver weight and proliferation increased in ASMase null mice following partial hepatectomy compared to ASMase ${ }^{+/+}$mice, probably due to their intrinsic phenotype 
(Supplementary Figure 9). Thus, the inhibition of ASMase reproduces the effects of genetic ablation of ASMase on symptoms of alcohol-induced liver injury, without compromising liver regeneration.

\section{Patients with AH exhibit increased expression of ASMase, ER stress markers and StARD1}

Given the above results, we next addressed the expression status of ASMase in patients with ALD. We compared the ASMase mRNA levels in liver biopsies from patients with acute $\mathrm{AH}$, whose characteristics are shown in Supplementary Table 1. In line with the preceding findings linking ASMase to ER stress, samples from patients with AH exhibited a 2-3-fold increase in the expression of ASMase as well as ER stress markers compared to control subjects (Figure 4 F-H). Moreover, StARD1 mRNA levels increased 7 fold in liver biopsies from $\mathrm{AH}$ patients with respect to samples from control subjects (Figure 4I). Thus, these findings support the potential relevance of ASMase in human ALD.

\section{Discussion}

These findings uncovered a novel role for ASMase in ALD. ASMase ${ }^{-/-}$mice are refractory to alcohol-induced ER stress, a critical mechanism involved in ALD, which regulates hepatic steatosis and liver injury $[4,27]$. The resistance to ER stress is specific for alcohol and not due to an inherent defect in ER stress response, as revealed by tunicamycin challenge in $\mathrm{ASMase}^{-/-}$mice, which results in hepatic steatosis.

Of note, the lack of ASMase is known to cause the lysosomal storage disease Niemann-Pick type A (NPA) disease, which is characterized by the accumulation of lipids such as sphingomyelin, cholesterol, glycosphingolipids, and bis-monoacylglycerol phosphate in the affected organs, particularly the brain and visceral organs such as liver. The subsequent formation of foam cells and the massive lysosomal proliferation are thought to contribute to the known hepatomegaly in NPA disease [45]. These changes in the liver are variable as they are age-dependent, being more prominent in older mice (>12-14 weeks of age) [46].

In addressing the mechanisms of resistance of ASMase null mice to alcohol-induced ER stress we provide evidence that both ASMase ${ }^{+/+}$mice and ASMase $^{-/}$mice exhibit hyperhomocysteinemia induced by alcohol, and yet only the ASMase $^{+/+}$mice display signs of alcohol-mediated ER stress; moreover, alcohol-mediated hyperhomocysteinemia is independent of ASMase. In principle the fact that ASMase null mice are refractive to alcohol-induced ER stress despite exhibiting increased levels of homocysteine induced by alcohol does not distinguish whether the dependence of homocysteine on ASMase to cause ER stress is mediated by ASMase itself or due to secondary changes caused by the lack of ASMase. However, we provide evidence favoring the former possibility. First, exogenous ASMase uprgulates the expression of ER stress markers both in HepG2 cells or primary hepatocytes. Of relevance, ASMase inhibition in wild type mice by amitriptyline prevents alcohol-induced ER stress without abolishing alcohol-mediated hyperhomocysteinemia. Interestingly, our data are consistent with recent reports indicating that ASMase is required for homocysteine-induced glomerular injury in $\mathrm{CBS}^{-/}$mice, a genetic model of hyperhomocysteinemia [31]. In contrast to our findings with oral alcohol intake, intragastric alcohol infusion induces ER stress due to increased Hcy levels [4, 27]. Compared to the 3-4 fold higher plasma Hcy levels in mice fed alcohol orally, this effect was more pronounced (7-10 fold) in intragastric alcohol-fed mice [27], suggesting a threshold phenomenon for Hcy to induce ER stress. Intriguingly, however, recent findings reported that supplemention of MCD diet with Hcy attenuated MCD diet-induced hepatic ER stress and UPR activation and protected mice against MCD-induced steatohepatitis, despite a 7-10 fold increase in Hcy levels [47]. Moreover, mice fed a control diet supplemented with Hcy exhibited 3-6fold elevation in plasma Hcy but demonstrated no pathophysiologic changes [47]. Whether 
differences in treatment (MCD vs alcohol), sex (females vs males) or genetic background (FVB/NJ vs. C57BL/6) determined the contribution of Hcy to ER stress remains to be established. Thus, it could be argued that alcohol-induced hepatic ER stress can be caused independently by hyperhomocysteinemia and ASMase activation, suggesting that the participation of the former might be determined by the severity of hyperhomocysteinemia (Fig. 8E)

We hypothesized that ASMase could induce ER stress. While exogenous ASMase increased expression of ER stress markers, incubation of hepatocytes with NSMase from bacillus cereus failed to induce these changes despite similar ceramide generation [34]. These findings fit with the notion that the effects of ceramide depend on the site of intracellular generation and imply that the activation of ASMase in acidic endolysosomal compartments is functionally linked to ER homeostasis. Previous findings in HeLa cells reported that ceramide released $\mathrm{Ca}^{2+}$ from the ER to the cytosol [48]. Consistent with a key, role of $\mathrm{Ca}^{2+}$ to maintain ER homeostasis and that $\mathrm{ER} \mathrm{Ca}^{2+}$ loss results in ER stress [49], we provide evidence that ASMase decreased thapsigargin-induced $\mathrm{ER} \mathrm{Ca}^{2+}$ release, suggesting lower ER $\mathrm{Ca}^{2+}$ content induced by ASMase. Of interest, the stimulation of ER $\mathrm{Ca}^{2+}$ release by exogenous ASMase preceded the expression of ER stress markers. Overall, our findings fit with the concept that aberrant lipid composition in the ER regulates SERCA and hence ER $\mathrm{Ca}^{2+}$ homeostasis [29]. Whether ASMase activation modulates SERCA activity in the ER by perturbing ER membrane physical properties remains to be examined. In support for endolysosomal/ER relationship, previous findings in NPC1 disease have shown that stimulation of ER $\mathrm{Ca}^{2+}$ release via SERCA by thapsigargin or curcumin to the cytosol overcomes reduced lysosomal $\mathrm{Ca}^{2+}$ in NPC1 null cells, correcting endocytic transport [50]. Further work remains to be done to fully understand the mechanism whereby ASMaseinduced ceramide generation in endolysosomes stimulates $\mathrm{ER} \mathrm{Ca}^{2+}$ release. Since NPC1 disease is characterized by increased accumulation of endolysosomal cholesterol and sphingolipids, it is conceivable that NPC1, whose physiological role is to transfer cholesterol from lysosomes to ER, may contribute to the transfer of ceramide from endolysosomes to ER.

The findings of mChol homeostasis in the $\mathrm{ASMase}^{-/-}$mice deserve further consideration. We observed a defective trafficking of cholesterol to mitochondria in ASMase $^{-/-}$mice that was associated with impaired expression of StARD1, a mitochondrial cholesterol transporting polypeptide $[39,40]$. Given the increased basal cholesterol levels in ASMase A- $^{-/}$ mice and unaltered expression of StARD1, it is concievable that mChol trafficking may depend on StARD1 upregulation and that the endogenous StARD1 levels may be saturated with existing cholesterol levels. Moreover, we provide evidence that StARD1 is an ER stress target gene, as its upregulation by tunicamycin is prevented by TUDCA. Our findings are consistent with previous data in NIH-3T3 cells showing that ER stress stimulated StARD5 expression but not of StARD4 or MLN64 [51], underscoring that the role of ER stress in regulating individual members of the StART family of lipid transporting is specific.

To address the applicability of the findings in $\mathrm{ASMase}^{-/-}$mice, we addressed the effects of pharmacological ASMase inhibition. Although recent studies reported that ASMase inhibition by imipramine ameliorated alcohol-induced hepatic steatosis and insulin resistance [24], the role of ASMase inhibition on alcohol-induced hepatic ER stress, liver injury and LPS susceptibility was not investigated. We show for the first time that ASMase inhibition with amitriptyline reduced alcohol-induced ER stress markers, and protected against alcohol-mediated sensitization to LPS-induced liver injury. These findings are in line with recent reports indicating a key role of ceramide in alcohol-induced ER stress and that myriocin, an inhibitor of de novo ceramide generation, modulates insulin signaling in liver slices from mice fed alcohol $[52,53]$. Consistent with the functional relationship between 
TNF and ASMase the resistance of ASMase ${ }^{-/}$mice to the deleterious effects of alcohol was reproduced in TNFR1/R2 ${ }^{-/}$mice. Importantly, the inhibition of ASMase by amitriptyline did not impair the recovery of the liver mass after PH. This feature is of significant relevance as defects in liver regeneration is a serious concern contributing to the fatal outcome in patients with acute AH [1,2]. Moreover, our data indicate enhanced expression of ASMase, StARD1 and ER stress markers in liver biopsies from patients with AH. Although StARD1 upregulation in patients suggests mChol loading, confirmation at this level would require larger size samples to determine cholesterol content in isolated mitochondria from patients. Overall, our study defines a previously unrecognized role of ASMase in ALD by inducing ER stress and downstream consequences, and suggests that targeting ASMase may be a novel therapeutic option to prevent alcohol-induced ER stress, mChol loading and TNF susceptibility without compromising liver regeneration.

\section{Supplementary Material}

Refer to Web version on PubMed Central for supplementary material.

\section{Acknowledgments}

We are indebted to Dr. Gökhan S. Hotamisligil (Harvard University) for insightful comments.

FINANCIAL SUPPORT: The work was supported by CIBEREHD, Fundació la Marató de TV3, la Mutua Madrileña, and grants PI10/02114, PI09/0056 and PI09/1164 (Instituto de Salud Carlos III), SAF2008-02199, SAF2009-11417, SAF2010-15760, SAF2011-23031, and SAF2012-34831 (Plan Nacional de I+D), Spain; and P50AA-11999 (Research Center for Liver and Pancreatic Diseases, NIAAA/NIH)

\section{ABBREVIATIONS}

$\begin{array}{ll}\text { ALD } & \text { Alcohol induced liver disease } \\ \text { ASMase } & \text { acid sphingomyelinase } \\ \text { BHMT } & \text { betaine homocysteine methyl transferase } \\ \text { CBS } & \text { cystathionine- -synthase } \\ \text { DGAT2 } & \text { diacylglycerol transferase 2 } \\ \text { ER } & \text { endoplasmic reticulum } \\ \text { FAS } & \text { fatty acid synthase } \\ \text { Hcy } & \text { homocysteine } \\ \text { MCD } & \text { methionine and choline deficient } \\ \text { mChol } & \text { mitochondrial cholesterol } \\ \text { mGSH } & \text { mitochondrial GSH } \\ \text { MS } & \text { methionine synthase } \\ \text { MAT1A } & \text { methionine adenosyl transferase 1A } \\ \text { NSMase } & \text { neutral sphingomyelinase } \\ \text { PH } & \text { partial hepatectomy } \\ \text { SM } & \text { sphingomyelin } \\ \text { Smgs1 } & \text { sphingomyelin synthase1 } \\ \text { Sgms2 } & \text { sphingomyelin synthase2 }\end{array}$




$\begin{array}{ll}\text { StARD1 } & \text { Steroidogenic Acute Regulatory Domain protein } \\ \text { SREBP } & \text { sterol regulatory element binding protein } \\ \text { TUDCA } & \text { tauroursodeoxycholic acid } \\ \text { UPR } & \text { unfolded protein response }\end{array}$

\section{References}

1. Tilg H, Diehl AM. Cytokines in alcoholic and nonalcoholic steatohepatitis. N Engl J Med. 2000; 343:1467-1476. [PubMed: 11078773]

2. Gao B, Bataller R. Alcoholic liver disease: pathogenesis and new therapeutic targets. Gastroenterology. 2011; 141:1572-1585. [PubMed: 21920463]

3. You M, Considine RV, Leone TC, Kelly DP, Crabb DW. Role of adiponectin in the protective action of dietary saturated fat against alcoholic fatty liver in mice. Hepatology. 2005; 42:568-577. [PubMed: 16108051]

4. Ji C, Kaplowitz N. ER stress: can the liver cope? J Hepatol. 2006; 45:321-333. [PubMed: 16797772]

5. Mato JM, Martinez-Chantar ML, Lu SC. Methionine metabolism and liver disease. Ann Rev Nutr. 2008; 28:273-293. [PubMed: 18331185]

6. Garcia-Ruiz C, Morales A, Colell A, Ballesta A, Rodés J, Kaplowitz N, Fernández-Checa JC. Feeding S-adenosyl-L-methionine attenuates both ethanol-induced depletion of mitochondrial glutathione and mitochondrial dysfunction in periportal and perivenous rat hepatocytes. Hepatology. 1995; 21:207-214. [PubMed: 7806156]

7. Wu D, Cederbaum AI. Oxidative stress and alcoholic liver disease. Sem Liver Dis. 2009; 29:141154.

8. Yin M, et al. Essential role of tumor necrosis factor alpha in alcohol-induced liver injury in mice. Gastroenterology. 1999; 117:942-952. [PubMed: 10500078]

9. Haybaeck J, Zeller N, Wolf MJ, Weber A, Wagner U, et al. A lymphotoxin-driven pathway to hepatocellular carcinoma. Cancer cell. 2009; 16:295-308. [PubMed: 19800575]

10. Colell A, García-Ruiz C, Miranda M, Ardite E, Marí MA, et al. Selective glutathione depletion of mitochondria by ethanol sensitizes hepatocytes to tumor necrosis factor. Gastroenterology. 1998; 115:1541-1551. [PubMed: 9834283]

11. Pastorino JG, Hoek JB. Ethanol potentiates tumor necrosis factor-alpha cytotoxicity in hepatoma cells and primary rat hepatocytes by promoting induction of the mitochondrial permeability transition. Hepatology. 2000; 31:1141-1152. [PubMed: 10796891]

12. Hannun YA, Luberto C. Ceramide in the eukaryotic stress response. Trends Cell Biol. 2000; 10:73-80. [PubMed: 10652518]

13. Morales A, Lee H, Goñi FM, Kolesnick R, Fernandez-Checa JC. Sphingolipids and cell death. Apoptosis. 2007; 12:923-939. [PubMed: 17294080]

14. Kolesnick RN, Kronke M. Regulation of ceramide production and apoptosis. Ann Rev Physiol. 1998; 60:643-665. [PubMed: 9558480]

15. Chipuk JE, McStay GP, A. Bharti A, Kuwana T, Clarke CJ, LJ, et al. Sphingolipid metabolism cooperates with BAK and BAX to promote the mitochondrial pathway of apoptosis. Cell. 2012; 148:988-1000. [PubMed: 22385963]

16. Angulo S, Morales A, Danese S, Llacuna L, Masamunt MC, et al. Probiotic sonicates selectively induce mucosal immune cell apoptosis through ceramide generation via neutral sphingomyelinase. PLoS One. 2011; 6:e16953. [PubMed: 21408067]

17. Zhang P, Liu B, Jenkins GM, Hannun YA, Obeid LM. Expression of neutral sphingomyelinase identifies a distinct pool of sphingomyelin involved in apoptosis. J Biol. Chem. 1997; 272:96099612. [PubMed: 9092485]

18. Brenner B, Ferlinz K, Grassmé H, Weller M, Koppenhoefer UJ, et al. Fas/CD95/Apo-I activates the acidic sphingomyelinase via caspases. Cell Death Differ. 1998; 5:29-37. [PubMed: 10200443] 
19. Garcia-Ruiz C, Colell A, Marí M, Morales A, Calvo M, et al. Defective TNF-alpha-mediated hepatocellular apoptosis and liver damage in acidic sphingomyelinase knockout mice. J. Clin. Invest. 2003; 111:197-208. [PubMed: 12531875]

20. Pena LA, Fuks Z, Kolesnick RN. Radiation-induced apoptosis of endothelial cells in the murine central nervous system: protection by fibroblast growth factor and sphingomyelinase deficiency. Cancer Res. 2000; 60:321-327. [PubMed: 10667583]

21. Edelmann B, Bertsch U, Tchikov V, Winoto-Morbach S, Perrotta C, et al. Caspase-8 and caspase-7 sequentially mediate proteolytic activation of acid sphingomyelinase in TNF-R1 receptosomes. EMBO J. 2011; 30:379-394. [PubMed: 21157428]

22. Moles A, Tarrats N, Morales A, Domínguez M, Bataller RJ, et al. Acidic sphingomyelinase controls hepatic stellate cell activation and in vivo liver fibrogenesis. Am. J. Pathol. 2010; 177:1214-1224. [PubMed: 20651240]

23. Deaciuc IV, Nikolova-Karakashian M, Fortunato F, Lee EY, Hill DB, McClain CJ. Apoptosis and dysregulated ceramide metabolism in a murine model of alcohol-enhanced lipopolysaccharide hepatotoxicity. Alcohol Clin. Exp. Res. 2000; 24:1557-1565. [PubMed: 11045865]

24. Liangpunsakul S, Rahmini Y, Ross RA, Zhao Z, Xu Y, Crabb DW. Imipramine blocks ethanolinduced ASMase activation, ceramide generation, and PP2A activation, and ameliorates hepatic steatosis in ethanol-fed mice. Am J Physiol. 2012; 302:G515-G523.

25. M. Mari F, Caballero A, Colell A, Morales J, Caballeria A, et al. Mitochondrial free cholesterol loading sensitizes to TNF- and Fas-mediated steatohepatitis. Cell Metab. 2006; 4:185-198. [PubMed: 16950136]

26. Tarrats N, Moles A, Morales A, Garcia-Ruiz C, Fernandez-Checa JC, et al. Critical role of tumor necrosis factor receptor 1 , but not 2 , in hepatic stellate cell proliferation, extracellular matrix remodeling, and liver fibrogenesis. Hepatology. 2011; 54:319-327. [PubMed: 21523796]

27. Ji C, Kaplowitz N. Betaine decreases hyperhomocysteinemia, endoplasmic reticulum stress, and liver injury in alcohol-fed mice. Gastroenterology. 2003; 124:1488-1499. [PubMed: 12730887]

28. Fu S, Watkins SM, Hotamisligil GS. The role of endoplasmic reticulum in hepatic lipid homeostasis and stress signaling. Cell Metab. 2012; 15:623-34. [PubMed: 22560215]

29. Fu S, Yang L, Li P, Hofmann O, Dicker LW, et al. Aberrant lipid metabolism disrupts calcium homeostasis causing liver endoplasmic reticulum stress in obesity. Nature. 2011; 473:528-31. [PubMed: 21532591]

30. Paton AW, Beddoe T, Thorpe CM, Whisstock JC, Wilce MC, Rossjoh J, Talbot UM, Paton JC. AB5 subtilase cytotoxin inactivates the endoplasmic reticulum chaperone BiP. Nature. 2006; 443:548-552. [PubMed: 17024087]

31. Boini KM, Xia M, Abais JM, Xu M, Li CX, Li PL. Acid sphingomyelinase gene knockout ameliorates hyperhomocysteinemic glomerular injury in mice lacking cystathionine- $\beta$-synthase. PLoS One. 2012; 7:e45020. [PubMed: 23024785]

32. Epstein S, Kirkpatrick CL, Castillon GA, Muñiz M, I. Riezman, et al. Activation of the unfolded protein response pathway causes ceramide accumulation in yeast and INS-1E insulinoma cells. J. Lipid Res. 2012; 53:412-20. [PubMed: 22210926]

33. Spassieva SD, Mullen TD, Townsend DM, Obeid LM. Disruption of ceramide synthesis by CerS2 down-regulation leads to autophagy and the unfolded protein response. Biochem. J. 2009; 424:273-283. [PubMed: 19728861]

34. García-Ruiz C, Marí M, Morales A, Colell A, Ardite E, et al. Human placenta sphingomyelinase, an exogenous acidic $\mathrm{pH}$-optimum sphingomyelinase, induces oxidative stress, glutathione depletion, and apoptosis in rat hepatocytes. Hepatology. 2000; 32:56-65. [PubMed: 10869289]

35. Bosch M, Marí M, Herms A, Fernández F, Fajardo A, et al. Caveolin-1 deficiency causes cholesterol-dependent mitochondrial dysfunction and apoptotic susceptibility. Curr. Biol. 2011; 21:681-686. [PubMed: 21497090]

36. Zhao P, Kalhorn TF, Slattery JY. Selective mitochondrial glutathione depletion by ethanol enhances acetaminophen toxicity in rat liver. Hepatology. 2002; 36:326-335. [PubMed: 12143040] 
37. Lamlé J, Marhenke S, Borlak J, von Wasielewski R, Eriksson CJ, Geffers R, Manns MP, Yamamoto M, Vogel A. Nuclear factor-eythroid 2-related factor 2 prevents alcohol-induced fulminant liver injury. Gastroenterology. 2008; 134:1159-1168. [PubMed: 18395094]

38. Mari M, Morales A, Colell A, García-Ruiz C, Kaplowitz N, Fernández-Checa JC. Mitochondrial glutathione: Features, regulation and role in disease. Biochim. Biophys. Acta. 2013; 1830:33173328. [PubMed: 23123815]

39. Miller WL, Bose HS. Early steps in steroidogenesis: intracellular cholesterol trafficking. J. Lipid Res. 2011; 52:2111-2135. [PubMed: 21976778]

40. Hall EA, Ren S, Hylemon PB, Rodriguez-Agudo D, Redford K, Marques D, Kang D, Gil G, Pandak WM. Detection of the steroidogenic acute regulatory protein, StAR, in human liver cells. Biochim. Biophys. Acta. 2005; 1733:111-119. [PubMed: 15863358]

41. Ozcan U, Yilmaz E, Ozcan L, Furuhashi M, Vaillancourt E, RO, et al. Chemical chaperones reduce ER stress and restore glucose homeostasis in a mouse model of type 2 diabetes. Science. 2006; 313:1137-1140. [PubMed: 16931765]

42. Jaruga B, Hong F, Kim WH, Sun R, Fan S, Gao B. Chronic alcohol consumption accelerates liver injury in T cell-mediated hepatitis: alcohol disregulation of NF-kappaB and STAT3 signaling pathways. Am. J. Physiol. Gastrointerst. Liver Physiol. 2004; 287:G471-G479.

43. Lang PA, Schenck M, Nicolay JP, Becker IU, Kempe DS, et al. Liver cell death and anemia in Wilson disease involve acid sphingomyelinase and ceramide. Nat Med. 2007; 13:164-170. [PubMed: 17259995]

44. Jenkins RW, Idkowiak-Baldys J, Simbari F, Canal D, Roddy P, et al. A novel mechanism of lysosomal acid sphingomyelinase maturation: requirement for carboxyl-terminal proteolytic processing. J. Biol. Chem. 2011; 286:3777-3788. [PubMed: 21098024]

45. Schuchman EH. Acid sphingomyelinase, cell membranes and human disease: lessons from Niemann-Pick disease. FEBS Lett. 2010; 584:1895-1900. [PubMed: 19944693]

46. Prinetti A, Prioni S, Chiricozzi E, Schuchman EH, Chigorno V, Sonnino S. Secondary alterations of sphingolipid metabolism in lysosomal storeage disease. Neurochem. Res. 2011; 36:1654-1668. [PubMed: 21207141]

47. Henkel AS, Elias MS, Green RM. Homocysteine supplementation attenuates the unfolded protein response in a murine nutritional model of steatohepatitis. J Biol. Chem. 2009; 284:31807-31816. [PubMed: 19762918]

48. Pinton P, Ferrari D, Rapizzi E, Di Virgilio F, Pozzan T, et al. The Ca2+ concentration in the endoplasmic reticulum is a key determinant of ceramide-induced apoptosis: significance for the molecular mechanism of Bcl-2 action. EMBO J. 2001; 20:2690-2701. [PubMed: 11387204]

49. Feng B, Yao PM, Li Y, Devlin CM, Zhang D, et al. The endoplasmic reticulum is the site of cholesterol-induced cytotoxicity in macrophages. Nat Cell Biol. 2003; 5:781-792. (2003). [PubMed: 12907943]

50. Lloyd-Evans E, Morgan AJ, He X, Smith DA, Elliot-Smith E, et al. Niemann-Pick disease type C1 is a sphingosine storage disease that causes deregulation of lysosomal calcium. Nat Med. 2008; 14:1247-1255. [PubMed: 18953351]

51. Soccio RE, Adams RM, Maxwell KN, Breslow JL. Differential gene regulation of StaRD4 and StaRD5 cholesterol transfer proteins. Activation of StaRD4 by sterol regulatory element-binding protein-2 and StARD5 by endoplasmic reticulum stress. J Biol Chem. 2005; 280:19140-19418.

52. Longato L, Ripp K, Setshedi M, Dostalek M, Akhlagi F, Branda M, Wands JR, de la Montse SM. Insulin resistance, ceramide accumulation and endoplasmic reticulum stress in human chronic alcohol-related liver disease. Oxid Med Cell Longev. 2012:479348. [PubMed: 22577490]

53. Lizarazo D, Zabala V, Tong M, de la Montse SM. Insulin/IGF and ER stress pathways in experimental alcohol-related steatohepatitis. J Biochem Pharmacol Res. 2013 in press. 
A

B

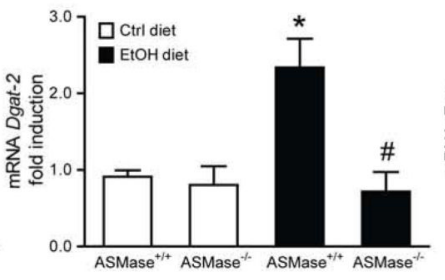

E

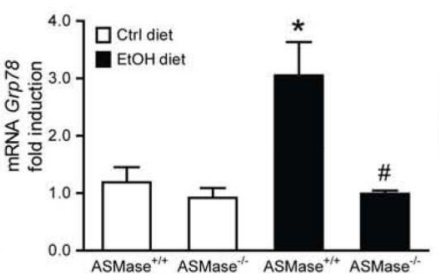

H

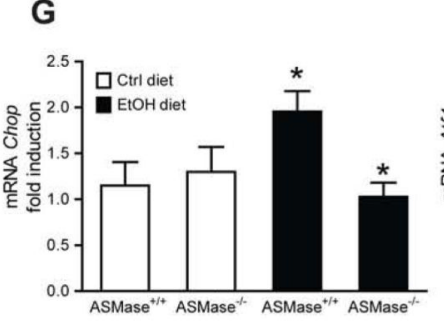

C

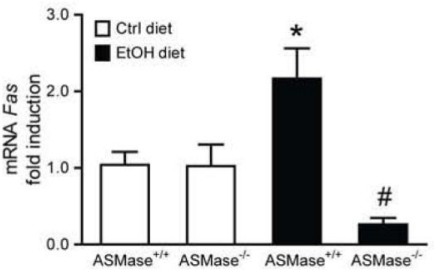

$\mathbf{F}$

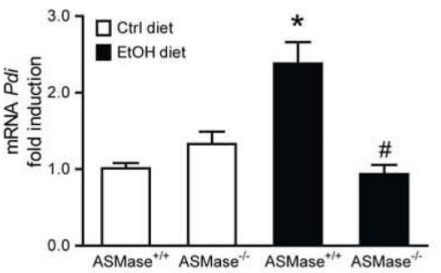

$\mathbf{K}$

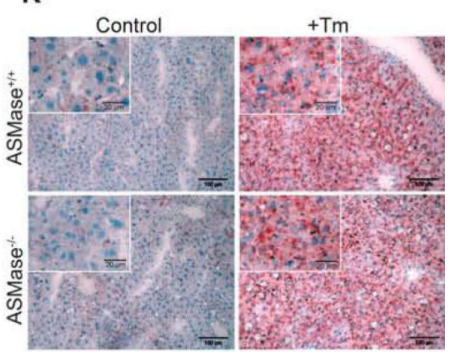

I

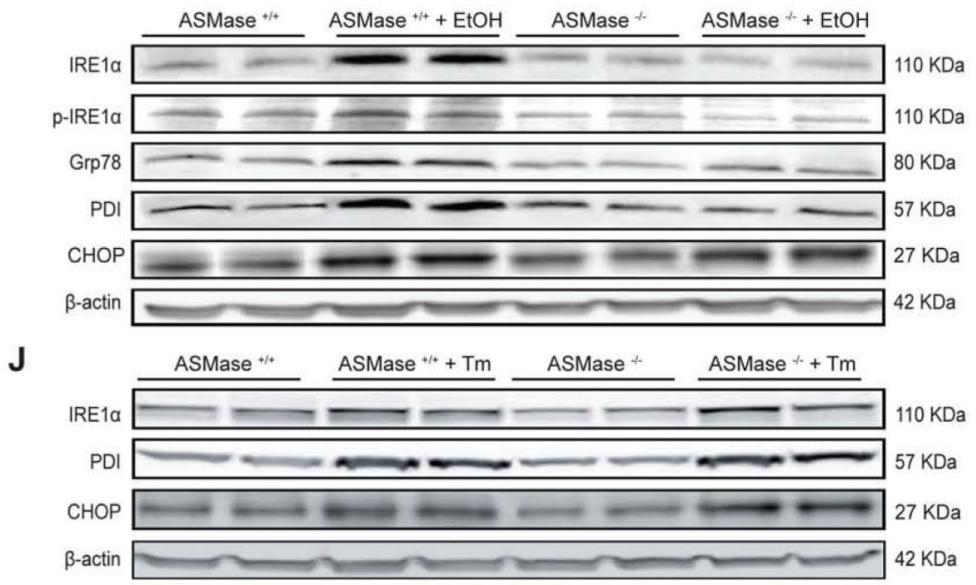

Fig. 1. ASMase is required for alcohol-mediated activation of lipogenesis and ER stress Liver samples from mice-fed alcohol were processed for expression of SREBP-1 (A), DGAT-2 (B), FAS (C), SREBP-2 (D) and ER stress markers at the mRNA level, GRP78 (E), PDI (F), CHOP (G), ATF-4 (H), and protein level (I). Livers from tunicamycin-treated mice in vivo (Tm, 1mg/kg, 24 hours) were processed for ER stress $(\mathbf{J})$ and oil red staining (K). Results are the mean \pm SD (6-7 mice per group). *p<0.05 vs. WT mice fed control diet, $\# \mathrm{p}<0.05$ vs. WT mice fed ethanol diet. 
A

Cytochrome C
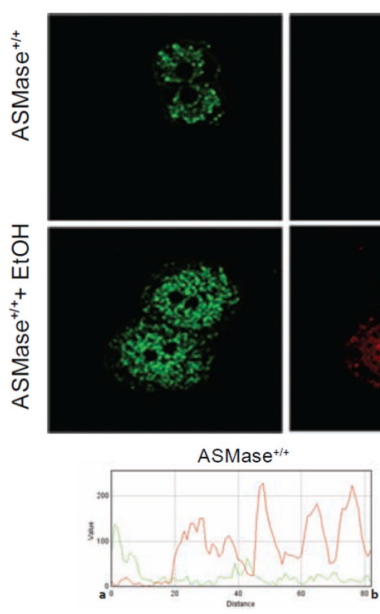

B
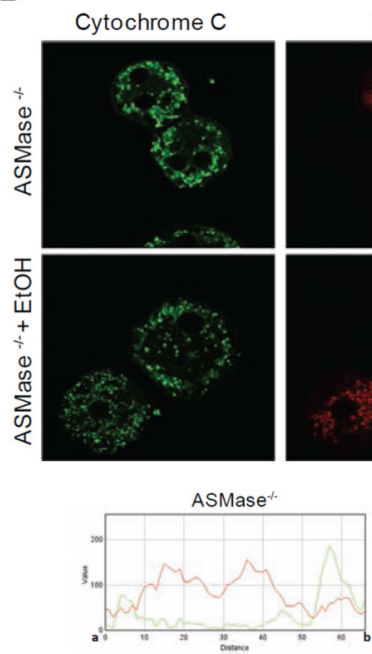

Filipin
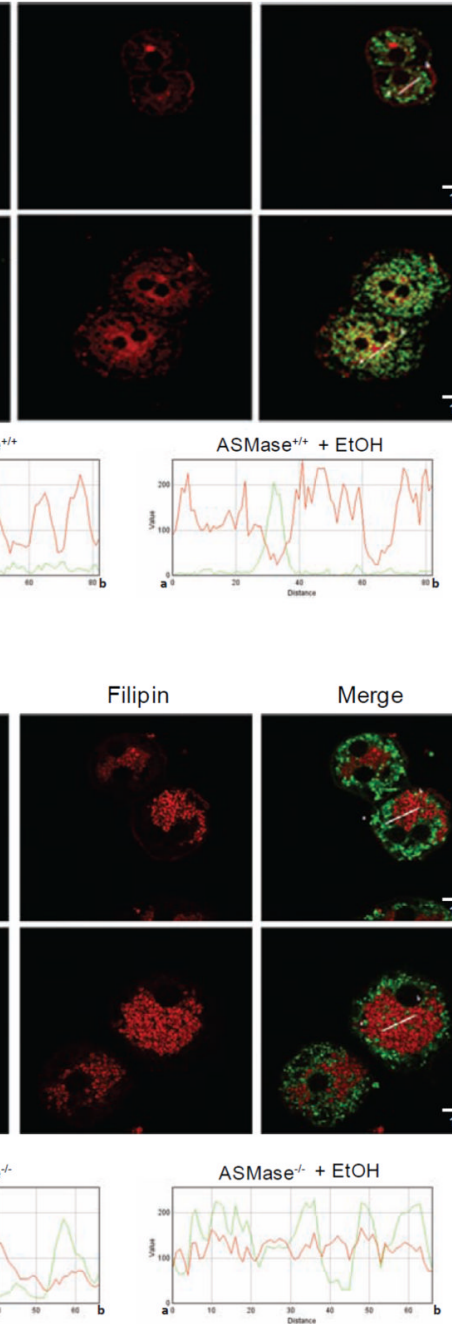

Merge

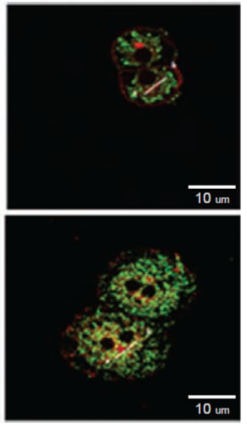

$\overline{10 \mathrm{um}}$
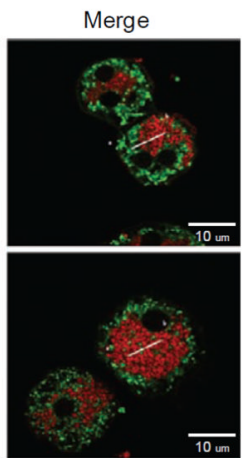
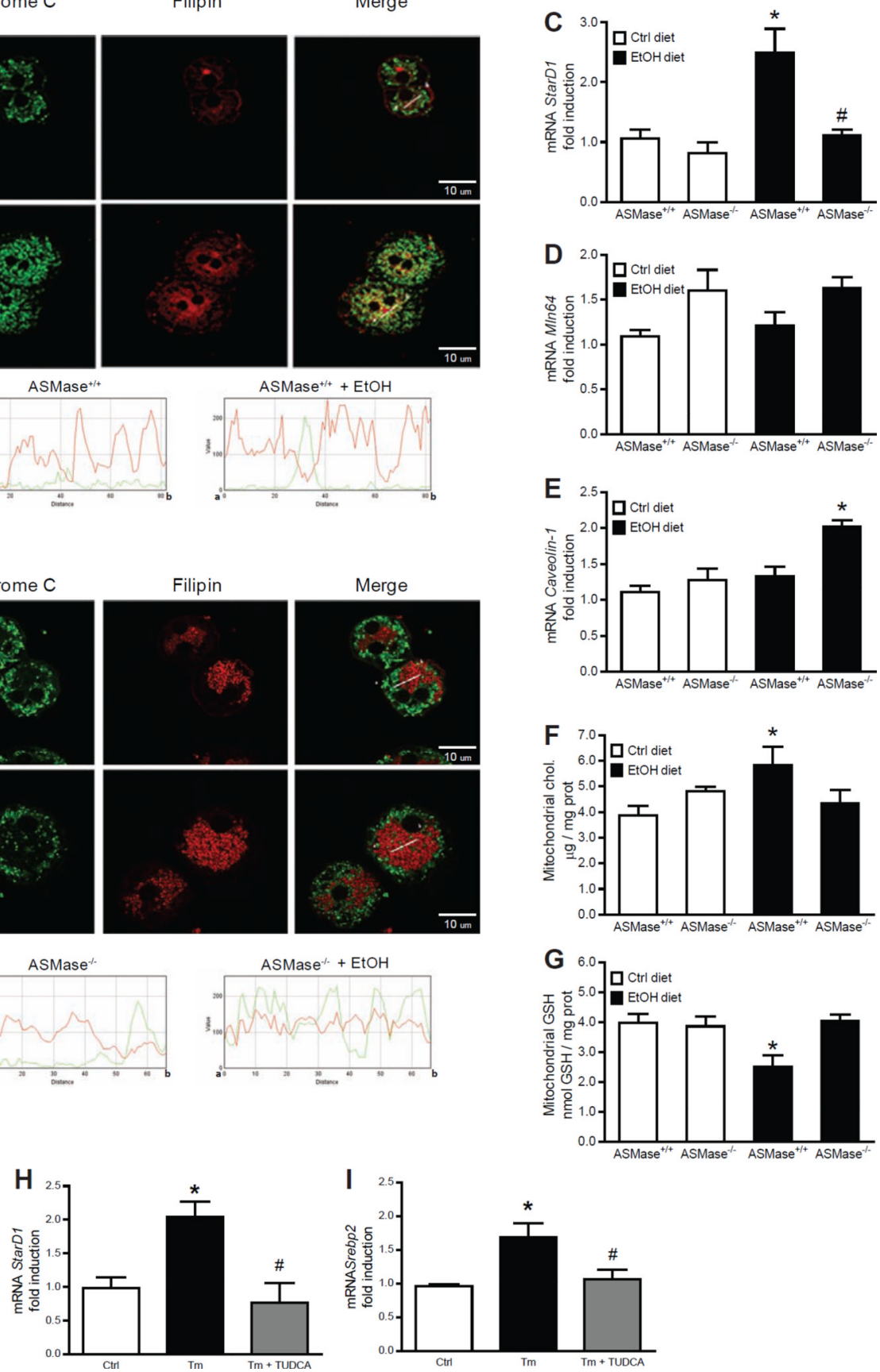

Fig 2. ASMase is required for alcohol induced $\mathrm{mChol} \mathrm{trafficking} \mathrm{and} \mathrm{mGSH}$ depletion Confocal imaging of hepatocytes to detect colocalization of cholesterol (filipin) with mitochondria (cytochrome c) (A, B). Liver samples were processed for StARD1, Mln64 and caveolin-1 expression ( $\mathbf{C}-\mathbf{E})$ and isolated mitochondria were analyzed for cholesterol (F) and GSH (G) levels. Results are the mean \pm SD (6 mice per group). ${ }^{*} p<0.01$ vs. WT mice fed control diet, \#p<0.01 vs. WT mice fed ethanol diet. StARD1 (H) and SREBP-2 (I) from HepG2 cells challenged with tunicamycin (Tm) with or without TUDCA. Results are the mean $\pm \mathrm{SD}(\mathrm{n}=4)$. ${ }^{*} \mathrm{p}<0.01$ vs. control cells, $\# \mathrm{p}<0.01$ vs. cells incubated with Tm. 
A
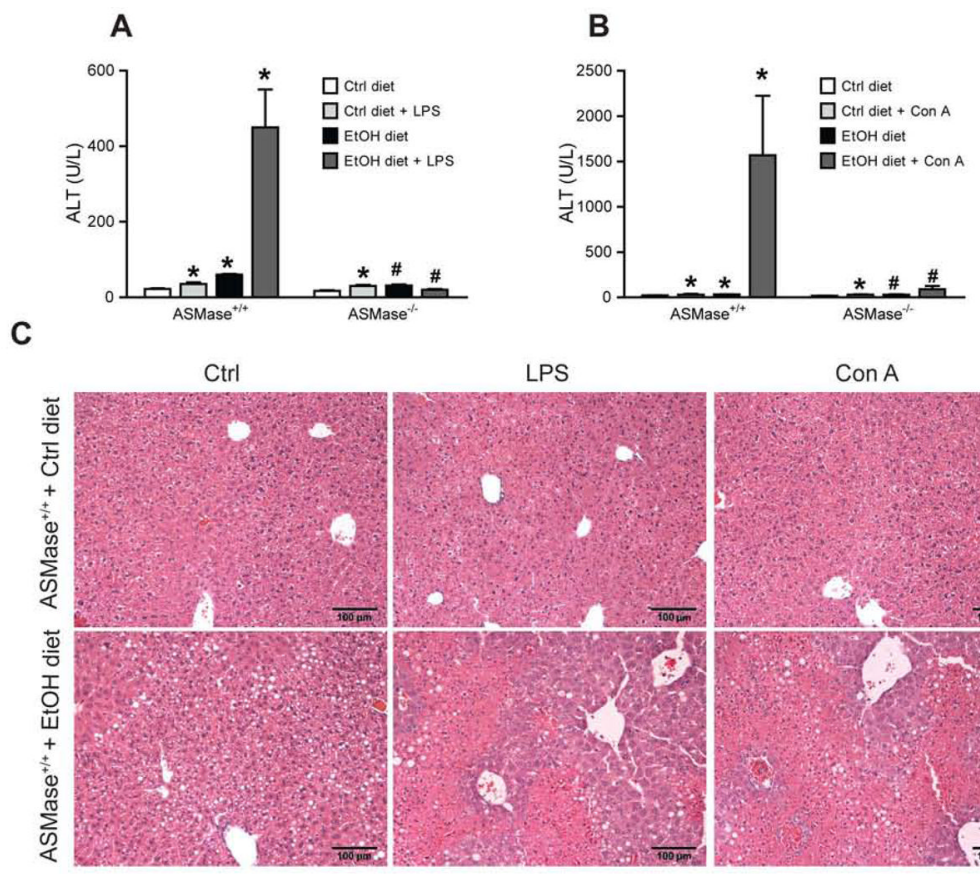

D
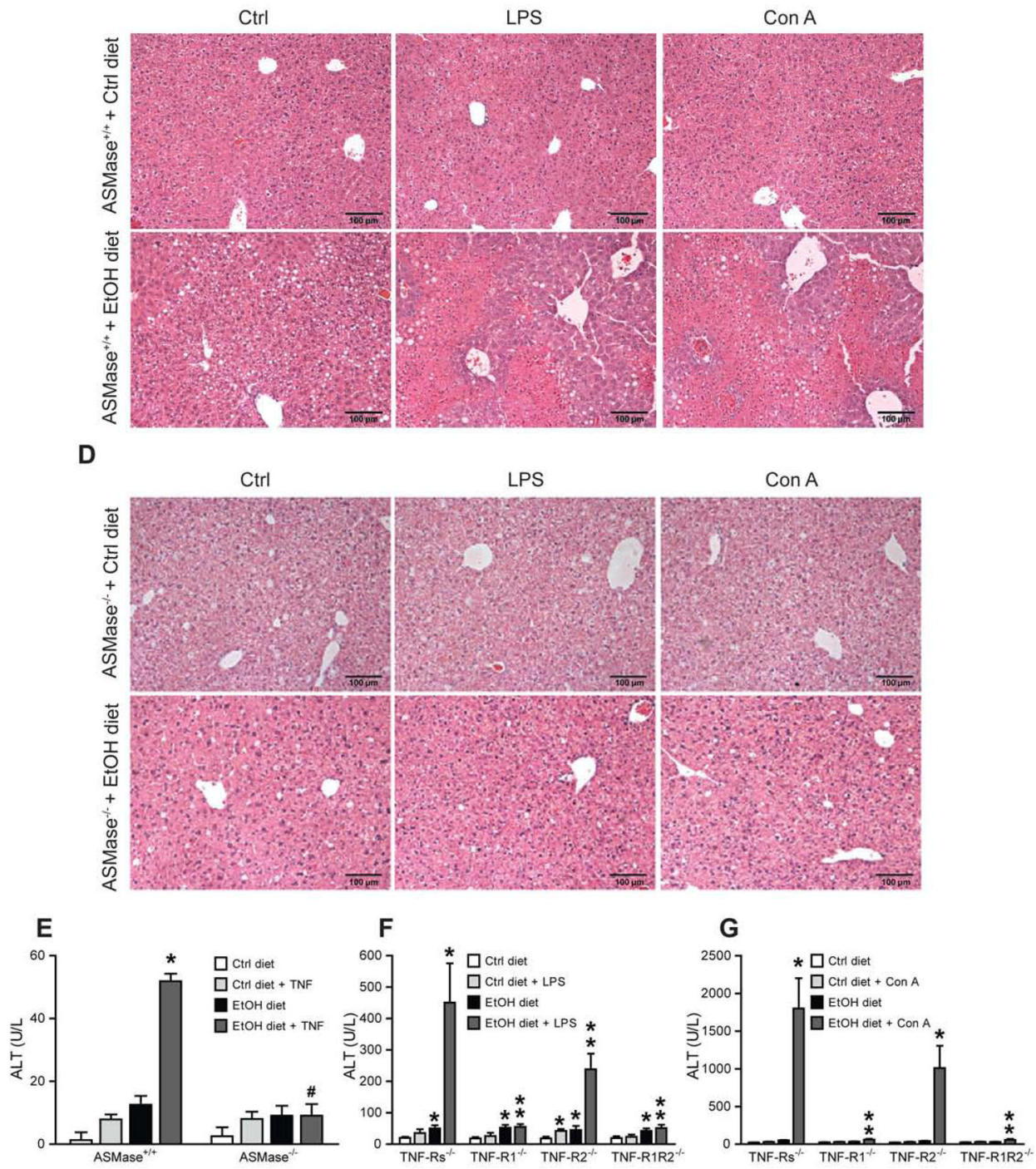

Fig 3. ASMase and TNFR1 deficiency prevent alcohol-induced sensitization to LPS/ConA Plasma and liver samples from alcohol-fed mice challenged with LPS or ConA were processed ALT (A, B) and histology analyses $(\mathbf{C}, \mathbf{D})$. (E) Susceptibility of primary hepatocytes to TNF (280ng/ml, 16h). Results are the mean \pm SD (6-8 mice per group). A-B, ${ }^{*} \mathrm{p}<0.05$ vs. WT mice fed control diet, \#p $<0.05$ vs. WT mice fed ethanol; E, $* \mathrm{p}<0.05$ vs. Ctrl $+\mathrm{TNF}$; \#p<0.05 vs. WT ethanol fed +TNF. ALT levels from TNF receptors null mice challenged with LPS $(\mathbf{F})$ or con-A $(\mathbf{G})$. Results are the mean \pm SD (7-9 mice per group). $* \mathrm{p}<0.05$ vs. WT mice fed control diet; **p $<0.05$ vs. WT mice fed ethanol diet+LPS or ConA. 
A
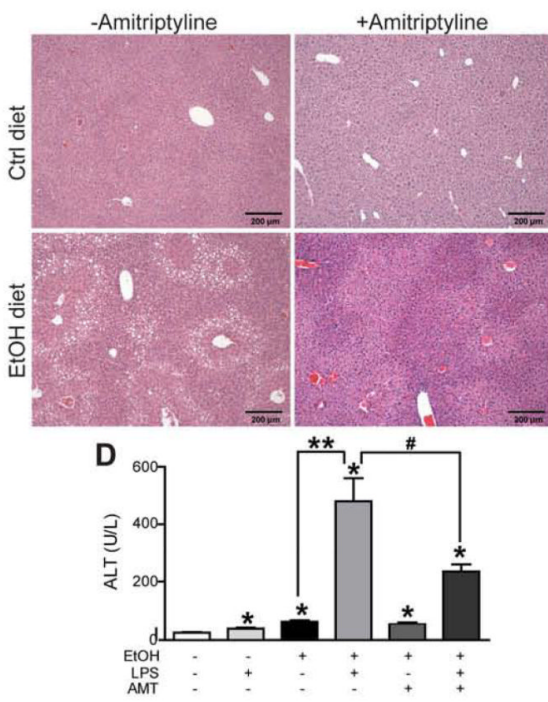

B

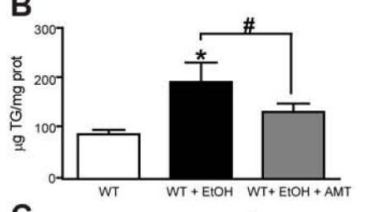

C

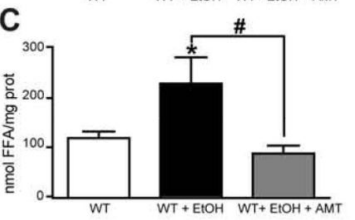

E

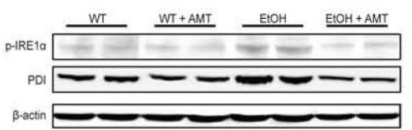

G
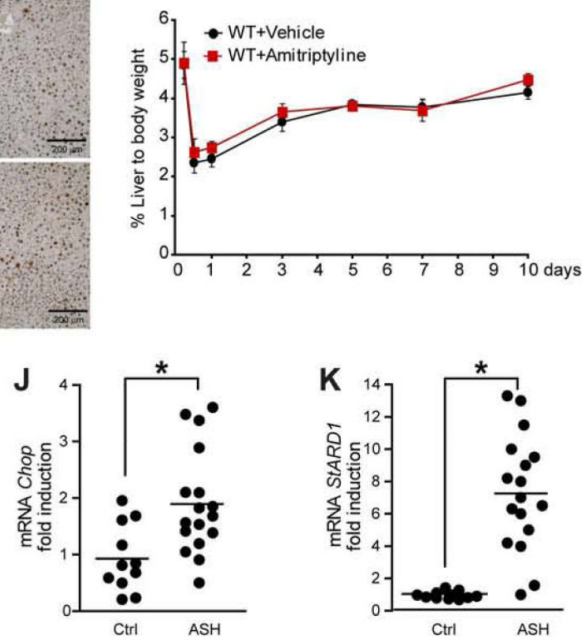

$\mathbf{F}$
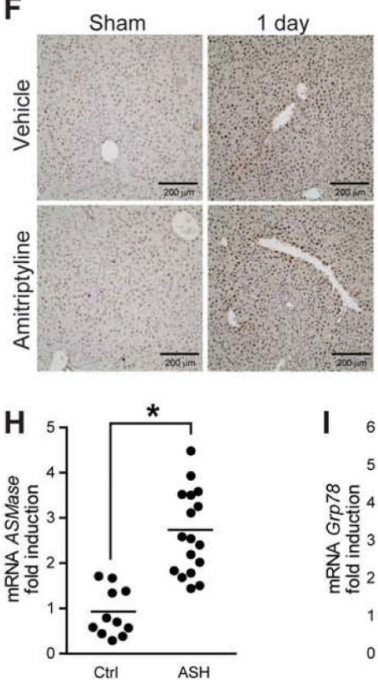
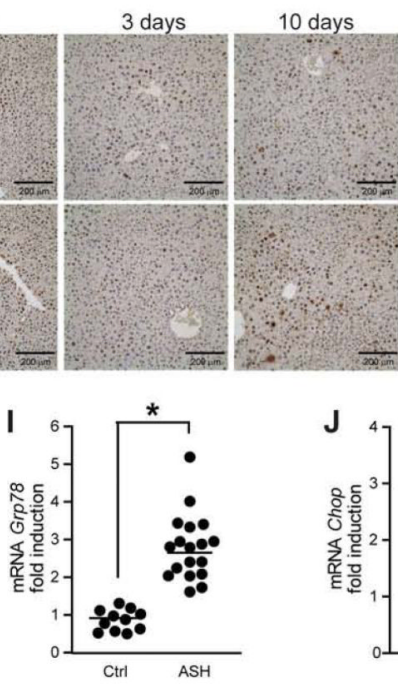

$\mathbf{L}$

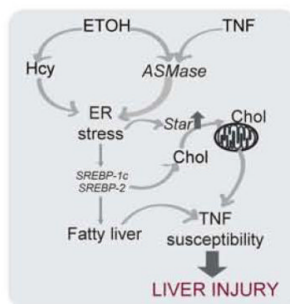

Fig 4. Pharmacological ASMase inhibition does not impair liver regeneration and its expression increases in liver samples from patients with $\mathrm{AH}$

Histology (A), liver TG (B), liver FFA (C), serum ALT (D), and expression of ER stress markers (E) in alcohol-fed wild-type mice treated with amitriptyline (AMT). PCNA staining (F) and liver weight $(\mathbf{G})$ of wild type mice with or without amitriptyline (AMT) following $\mathrm{PH}$. The time 0 point reflects the data from the control sham-operated mice. Results are the mean \pm SD (6 wild type mice per group). ${ }^{*} \mathrm{p}<0.05$ vs. mice fed control diet; $* * p<0.05$ vs. mice fed ETOH diet; \#p<0.05 vs. mice fed ethanol diet diet + LPS without AMT treatment. Liver ASMase (H), Grp/8 (I), Chop (J) and StARD1 (K) mRNA levels of patients with AH 
or control subjects. ${ }^{*} \mathrm{p}<0.05$ vs control subjects. $\mathbf{L}$, diagram of events summarizing the findings observed. 